\title{
Vehicle Lightweighting Energy Use Impacts in U.S.
}

\section{Light-Duty Vehicle Fleet}

Sujit Das ${ }^{*^{1}}$, Diane Graziano ${ }^{2}$, Venkata K.K. Upadhyayula ${ }^{3,}$,Eric Masanet ${ }^{3}$, Matthew Riddle ${ }^{2}$, and Joe Cresko ${ }^{4}$

*Corresponding author e-mail dass@ornl.gov; ${ }^{1}$ Oak Ridge National Laboratory, 2360 Cherahala

Blvd. Knoxville, TN 37832, USA; ${ }^{2}$ Argonne National Laboratory, Argonne, IL 60439, USA;

${ }^{3}$ Northwestern University, Evanston, IL 60208, USA; ${ }^{4}$ U.S. Department of Energy, Washington, DC 20585, USA; ${ }^{5}$ Umea University, SE-901 87 Umea, Sweden 


\title{
Vehicle Lightweighting Energy Use Impacts in U.S. Light-Duty Vehicle Fleet
}

\begin{abstract}
In this article, we estimate the potential energy benefits of lightweighting the light-duty vehicle fleet from both vehicle manufacturing and use perspectives using plausible lightweight vehicle designs involving several alternative lightweight materials, low- and high-end estimates of vehicle manufacturing energy, conventional and alternative powertrains, and two different market penetration scenarios for alternative powertrain light-duty vehicles at the fleet level. Cumulative life cycle energy savings (through 2050) across the nine material scenarios based on the conventional powertrain in the U.S. vehicle fleet range from -29 to 94 billion GJ, with the greatest savings achieved by multi-material vehicles that select different lightweight materials to meet specific design purposes. Lightweighting alternative-powertrain vehicles could produce significant energy savings in the U.S. vehicle fleet, although their improved powertrain efficiencies lessen the energy savings opportunities for lightweighting. A maximum level of cumulative energy savings of lightweighting the U.S. light-duty vehicle through 2050 is estimated to be 66.1 billion GJ under the conventional-vehicle dominated business-as-usual penetration scenario.
\end{abstract}

Keywords: Vehicle Lightweighting; Life Cycle Energy; Lightweight Materials; Alternative Vehicle Powertrain; Vehicle Fleet Energy

\section{Introduction}

With high gasoline prices earlier during this decade and new fuel economy and emission regulations for model years 2017-2025 that require car and light truck (i.e., light-duty vehicles) 
performance equivalent to $54.5 \mathrm{mpg}$ and reductions in greenhouse gas emissions to 163 grams per mile in 2025, the incentive to lightweight vehicles is stronger than ever before. In the next few years, vehicle lightweighting will accelerate considerably across the automotive industry, which generally favors lightweighting through material substitution, design optimization and adopting other advanced manufacturing technologies that do not compromise a vehicle's attributes and functionalities, such as occupant or cargo space, vehicle safety, comfort, and acceleration performance. ${ }^{1}$ While marginal improvements can be attained by substituting materials in existing designs, meeting expected mass reduction targets will require a systems approach to efficient designs that take advantage of the unique attributes of specific lightweight materials. Vehicle lightweighting encompasses a lower density and a 10-70\% mass savings potential of emerging lightweight materials than the conventional mild steel predominantly used in the vehicles today.

Analysts project that lightweight materials' share of all materials in the automotive sector will increase from 30 to 70 percent by 2030 (with high-strength steel considered as a lightweight material). ${ }^{2}$ Industry and technical experts have projected that by 2050 , there is the potential to reduce the weight of light-duty vehicles by 20 to $50 \% .^{3-6}$ The U.S. Department of Energy (DOE) Vehicle Technologies Program has several vehicle lightweighting passenger car goals, including a maximum $50 \%$ weight reduction in body and chassis systems by the end of this decade. Towards these goals, the DOE and the National Institute of Standards (NIST) have both contributed to the development and validation of advanced materials, manufacturing technologies or materials models to support lightweight material adoption, and the automotive industry has pursued development work and is selectively applying lightweight materials. ${ }^{7-10}$ 
Along with advanced high-strength steel (AHSS), cast aluminum, and glass fiber compositeslightweight materials already in use in today's vehicles - there are several commercially available materials that could be used for lightweighting if they meet cost and manufacturability targets. These materials - carbon fiber composites, sheet aluminum, cast magnesium, and titanium - are used extensively in the aerospace industry where cost acceptance is up to an order of magnitude higher and production rates are several orders of magnitude lower than in the automotive industry. The amount of weight saved in a passenger vehicle when a lightweighted part potentially replaces a conventional auto part depends on two factors: selection of a lightweighted candidate material itself, and the nature of intended application. The mass reduction potentials of lightweighted materials considered in the study and their current and projected applications in production of lightweighted vehicles is summarized in the SI, Table S1.1 and S1.2, respectively. In both types of applications (i.e., strength- or stiffness-related parts), carbon fiber composites offer the most weight savings potential but at a cost premium of 1.5 - 5 times that of conventional steel. AHSS, aluminum, magnesium, and titanium do not provide any weight savings for parts where geometries and applications are not subject to buckling and bending, since these materials' modulus/density are identical to steel. Both vehicle-based ${ }^{11-15}$ and fleet-based ${ }^{14,16-20}$ LCA studies of lightweighting have been reported in the literature. Many of these studies focus on conventional vehicles and present comparative analysis of manufacturing and use phase impacts of specific lightweight materials (e.g., aluminum) relative to existing steel counterparts. ${ }^{13,15,17-24}$ LCA studies of alternative vehicles have also been reported. ${ }^{16,25}$ Fleet-based LCA results vary from one-time estimates ${ }^{14,17,20}$ of whole fleet conversion to time dependent estimates ${ }^{16,19,26}$ that consider vehicle market penetration. For example, with the objective of evaluating the system-wide energy impacts of the 
2016 CAFE standards, Cheah et al. $(2010)^{16}$ report LCA results for four vehicle scenarios lightweighting, downsizing, advanced powertrains, and a combination of the three strategies. The present study complements and extends previous work by considering all major candidate lightweight materials and vehicle design combinations in both conventional and alternative powertrain vehicles together in a consistent life-cycle modeling framework, and by assessing multiple vehicle penetration scenarios for more comprehensive results of potential future economy-wide fleet-level impacts. As such, the present study provides energy analysts, policy makers, and vehicle engineers with more robust quantitative information than previous studies on the possible life-cycle energy implications of different vehicle lightweighting strategies under different deployment conditions, which can lead to more informed lightweighting technology research, investment, and policy decisions.

In this article, we estimate the potential energy savings of lightweighting the light-duty vehicle fleet from both vehicle manufacturing and use perspectives. The assessment is based on plausible lightweight vehicle designs that capture the alternative lightweight materials being considered by the automotive industry today. Low-end and high-end estimates of vehicle-manufacturing energy are made for these lightweight vehicle types to reflect the potential to reduce vehiclemanufacturing energy with the adoption of efficient material and manufacturing technologies. We consider impacts in both conventional (nine different vehicle material-intensive types) and alternative (four different electric types) powertrains and capture a range of possible vehicle lightweighting energy savings by considering two different market penetration scenarios for four different types of alternative powertrain considered, light-duty vehicles at the fleet level, including vehicle stock turnover. The vehicle fleet-level analysis with the manufacturing energy consideration addresses the research objectives of this paper by estimating the relative energy 
use impacts for competing vehicle lightweighting strategies through 2050. A block diagram outlining the scope of current study is shown in Figure 1, including various conventional and alternative powertrain vehicle types considered in this study.
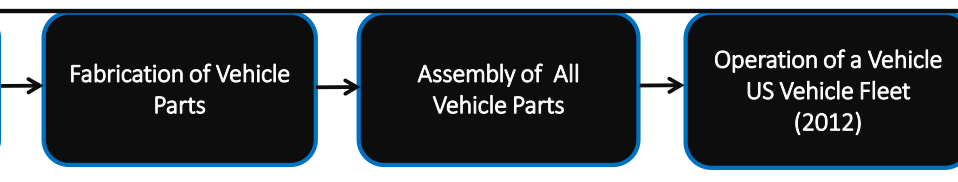

Operation of a Vehicle

US Vehicle Fleet

(2050)

- Nine Conventional Lightweighted Powertrain Vehicles Scenarios Considered

$>$ Steel intensive vehicle (SIV), aluminum intensive vehicle (AIV), titanium intensive vehicle (TIV), magnesium intensive vehicle $(\mathrm{MgV})$, glass fiber vehicle (GFV), carbon fiber vehicle (CFV), and three multi material lightweighted vehicles (10\% LW, $22 \% \mathrm{LW}$ and $38 \% \mathrm{LW})$.

$>$ Energy impacts of each of these lightweighted vehicle scenarios is compared with regular steel based current light duty vehicle which is considered as a baseline.

- $\quad$ Four Alternative Lightweighted Powertrain Vehicles Scenarios Considered

> Lightweighted versions of hybrid electric vehicle (LWHEV), plug in hybrid electric vehicle (LWPHEV), battery electric vehicle (LWBEV) and fuel cell vehicle (LWFCV).

$>$ Energy impacts are compared with their normal counterparts which are considered as a baseline. Thus, energy impacts of LWHEV are compared with HEV; LWPHEV with PHEV; LWBEV with BEV; and LWFCV with FCV.

- Energy Impacts of US vehicle fleet are calculated using two scenarios for the mix of powertrains in the fleet.

$>$ Annual energy outlook (AEO) and transportation energy futures (TEF) market scenarios.

Figure 1. System Boundary and Scope of Current Study

\subsection{Current Light-Duty Vehicle Materials Composition and Manufacturing Energy}

The automotive enterprise encompasses a complex supply chain that includes producing raw materials; forming and fabricating parts, components, and subsystems; assembling hundreds of these elements to make the vehicles; and distributing and selling the vehicles. Lightweight materials are currently more energy-intensive to manufacture than conventional steel, and so their adoption may impact vehicle manufacturing energy. Embodied material production energy is a significant share of the total automotive part manufacturing energy use, varying in the range 
of $40-90 \%$ depending on the material used, compared to $10-60 \%$ for part manufacturing and vehicle assembly. ${ }^{27-28}$

The complete material composition of a 2009 light-duty vehicle that represents a composite average of automobiles, light trucks, and utility trucks is presented in the SI, Table S2.1 ${ }^{29}$ About $40 \%$ of total vehicle weight is conventional mild steel. Today's vehicles contain a significantly lower amount of lightweight materials, two commonly used lightweight materials (i.e., aluminum and plastics/plastic composites) are in the range of 130-180 kg/vehicle each, compared to $0-5 \mathrm{~kg}$ for other lightweight materials (i.e., magnesium, titanium, and carbon fiber reinforced polymer composites). Using the available embodied energy data of various materials, total embodied energy of material production per an average light-duty vehicle is estimated to be about 107 GJ as shown in the SI, Table S2.1. Considering the 2012 domestic car and light truck production of 4 and 6 million, respectively, total annual embodied energy of material production of light-duty vehicle parts is estimated to be 1070 million GJ. ${ }^{29}$

Primary energy consumed for part manufacturing and vehicle assembly stage of the vehicle life cycle is estimated to be around $4 \%$ of total life cycle energy use, and a recent estimate using a bottom-up approach indicates a primary energy consumption of $34 \mathrm{GJ} /$ vehicle, or 340 million GJ for domestic production of 10 million light-duty vehicles, ${ }^{30}$ compared to a similar estimate of 360 million GJ from the 2011 data of Annual Survey of Manufacturers. ${ }^{31}$ Of this total, 120 million GJ of primary energy or 70 million GJ site energy is consumed for vehicle manufacturing by automotive original equipment manufacturers (OEMs) at their manufacturing facilities. In terms of primary energy, total automotive manufacturing energy use was about 1440 million GJ in 2011, about 5\% of total U.S. industrial sector energy use. ${ }^{32}$ Many opportunities to reduce this usage exist, particularly in developing more efficient technologies and materials ${ }^{33}$, 
implementing best energy management practices, and increasing use of energy resources such as waste heat.

\section{1 Lightweight Vehicle Scenarios}

Material composition and weights of lightweighted conventional and alternative powertrain vehicles are shown in Table 1 and 2, respectively, are assumed to be available depending on the two market penetration scenarios considered here. There are a number of pathways to lightweighting vehicles and a number of alternative powertrains that can be applied to conventional and lightweight material vehicles. For this assessment, researchers developed six lightweight vehicle types that focus on a specific material and three types that combine multiple materials to achieve specific weight-reduction targets. Four lightweighted, alternative-powertrain vehicles are also considered.

The material replacements in these vehicle types are described in greater detail in the SI, under S3. The selections for materials replacements are derived from data available in the research and trade literature about lightweight materials applications. ${ }^{4,34-41}$ Different lightweight material composition vehicle scenarios do implicitly harmonize for constant performance. Total mass savings estimates in each case obtained from the literature do implicitly include both primary and secondary mass savings, the latter savings type allow to maintain the constant performance using the same material type as for primary mass savings in some cases. Also the alternative- 
Table 1. Material Composition of Conventional Powertrain Lightweight Vehicles (kg)

\begin{tabular}{|c|c|c|c|c|c|c|c|c|c|c|}
\hline Material & Baseline & SIV & AIV & TIV & CFV & MgV & GFV & $\begin{array}{l}10 \% \\
\mathrm{LW}\end{array}$ & $\begin{array}{l}22 \% \\
\text { LW }\end{array}$ & $\begin{array}{l}38 \% \\
\mathrm{LW}\end{array}$ \\
\hline Mild Steel & 681 & 363 & 274 & 681 & 328 & 480 & 465 & 185 & 118 & 26 \\
\hline High-strength steel & 195 & 104 & 50 & 159 & 94 & 195 & 195 & 109 & 79 & 15 \\
\hline AHSS & 56 & 363 & 41 & 56 & 56 & 56 & 56 & 170 & 349 & 154 \\
\hline Other steel & 187 & 187 & 187 & 187 & 187 & 132 & 127 & 246 & 76 & 35 \\
\hline Aluminum Cast & 114 & 114 & 160 & 114 & 114 & 54 & 114 & 165 & 247 & 167 \\
\hline $\begin{array}{l}\text { Aluminum } \\
\text { Wrought }\end{array}$ & 33 & 33 & 298 & 33 & 33 & 15 & 33 & 84 & 90 & 86 \\
\hline Magnesium & 5 & 5 & 5 & 5 & 5 & 180 & 5 & 12 & 18 & 176 \\
\hline $\begin{array}{l}\text { Plastics and Plastic } \\
\text { Composites }\end{array}$ & 174 & 174 & 174 & 174 & 401 & 174 & 314 & 181 & 174 & 176 \\
\hline Other* & 330 & 330 & 330 & 348 & 330 & 223 & 330 & 446 & 234 & 264 \\
\hline Total (kg) & 1776 & 1674 & 1520 & 1758 & 1549 & 1510 & 1641 & 1598 & 1385 & 1101 \\
\hline
\end{tabular}

Table 2. Material Composition of Alternative Powertrain Lightweight Vehicles (kg)

\begin{tabular}{|l|l|l|l|l|l|l|l|l|l|}
\hline Material & Baseline & HEV & $\begin{array}{l}\text { LW } \\
\text { HEV }\end{array}$ & PHEV & $\begin{array}{l}\text { LW } \\
\text { PHEV }\end{array}$ & BEV & $\begin{array}{l}\text { LW } \\
\text { BEV }\end{array}$ & FCV & $\begin{array}{l}\text { FCV } \\
\text { Mild Steel }\end{array}$ \\
681 & 681 & 118 & 681 & 118 & 573 & 106 & 573 & 106 \\
\hline HSS & 195 & 195 & 79 & 195 & 79 & 165 & 71 & 165 & 71 \\
\hline AHSS & 56 & 56 & 349 & 56 & 349 & 47 & 312 & 47 & 312 \\
\hline Other steel & 187 & 187 & 76 & 187 & 76 & 157 & 68 & 157 & 68 \\
\hline Aluminum Cast & 114 & 114 & 247 & 114 & 247 & 105 & 221 & 105 & 221 \\
\hline $\begin{array}{l}\text { Aluminum } \\
\text { Wrought }\end{array}$ & 33 & 33 & 90 & 33 & 90 & 30 & 80 & 30 & 80 \\
\hline Magnesium & 5 & 5 & 18 & 5 & 18 & 5 & 16 & 5 & 16 \\
\hline $\begin{array}{l}\text { Plastics\& plastic } \\
\text { composites }\end{array}$ & 174 & 174 & 174 & 174 & 174 & 174 & 156 & 174 & 156 \\
\hline Other & 330 & 330 & 235 & 330 & 235 & 330 & 210 & 330 & 210 \\
\hline Battery & 0 & 35 & 27 & 43 & 34 & 619 & 472 & 22 & 16 \\
\hline $\begin{array}{l}\text { Motor \& } \\
\text { Controller }\end{array}$ & 0 & 83 & 64 & 82 & 64 & 16 & 13 & 115 & 89 \\
\hline Fuel Cell Stack & 0 & 0 & 0 & 0 & 0 & 0 & 0 & 103 & 87 \\
\hline $\begin{array}{l}\text { Fuel Cell } \\
\text { Auxiliaries }\end{array}$ & 0 & 0 & 0 & 0 & 0 & 0 & 0 & 248 & 211 \\
\hline Total (kg) & $\mathbf{1 7 7 6}$ & $\mathbf{1 8 9 4}$ & $\mathbf{1 4 7 6}$ & $\mathbf{1 9 0 1}$ & $\mathbf{1 4 8 2}$ & $\mathbf{2 2 2 0}$ & $\mathbf{1 7 2 2}$ & $\mathbf{2 0 7 3}$ & $\mathbf{1 6 4 1}$ \\
\hline
\end{tabular}


powertrain components including battery are sized appropriately for the vehicle weight, so powertrain components in the lightweighted vehicles have less mass than the comparable components in the baseline-weight vehicles. Powertrain components, sizing and efficiencies taken from trade and research literature are provided in the SI, Section S4. ${ }^{35,43}$

Although most of the vehicle designs focus on a single material, it is likely that a multi-material design with a blend of near-, mid-, and long-term material research will be preferred by OEMs since a single-material focus increases the risk and will delay introduction of intermediate lightweighting technologies. In most cases, the amounts of lightweight materials in the vehicle type presented here are derived from percentage material composition of lightweight vehicles. Using percentage weights avoids the problem of different vehicle weights used in various studies. To reach the maximum future vehicle lightweighting potential, each of the four major vehicle component groups (i.e., body, powertrain, chassis and suspension, and interior) must contribute to the weight reduction. For different lightweight vehicles, lightweight materials are assumed to replace the appropriate steel material content in the baseline vehicle.

\subsection{Modeling of Manufacturing Energy Impacts per Lightweighted Vehicle}

Cumulative energy demand (CED) for manufacturing of conventional and alternative powertrain vehicles is estimated in two steps. First, the energy intensities of three life cycle stages associated with vehicle manufacturing are summed up. These include:

(a) Primary Energy Intensity: the embodied energy content of materials that will be utilized in building an automobile. This includes energy intensity of raw material manufacturing (i.e. extraction and processing steps, e.g. MJ/kg of primary steel).

(b) Secondary Energy Intensity: the energy incurred during fabrication of $1 \mathrm{~kg}$ of material into finished auto parts, expressed as MJ/1kg of fabricated part (e.g. MJ/ kg of steel stamped). 
(c) Tertiary Energy Intensity: the energy invested by an automotive OEM at their production facility. This accounts for energy consumption of final vehicle assembly, machining, vehicle painting, HVAC and lighting, heating, welding, and other operations) and is normally expressed on a vehicle basis.

The total energy intensity of each material is then multiplied by mass of the respective material that went into production of vehicle to yield CED for that material. Individual CEDs are summed up to give total CED of vehicle.

Further, the manufacturing energy intensities for major automotive materials are estimated based on three criteria: (a) differences in energies associated with the raw material manufacturing routes; (b) production mix of primary and secondary (produced by scrap recycling) materials; and (c) component mix of vehicle parts produced from virgin and recycled materials. These three conditions either individually or in combination will determine the vehicle's manufacturing energy intensities that can vary by a large extent. To accommodate this large variation, two energy pathways are considered, one being the low energy pathway (LEP) and other one is high energy pathway (HEP). The manufacturing energy intensities (MJ/kg of an auto part) of producing major material auto parts (i.e. steel, aluminum, magnesium, titanium, and glass and carbon fiber reinforced polymer composite based auto parts) that are either currently used or potentially to be used by lightweighted cars in future are estimated and shown in the SI, Sect. S5. Relevant assumptions made in calculating manufacturing energy intensities of parts are also described there. Further, manufacturing energy intensities of all other material parts (including for alternative powertrain components) used by a passenger car are summarized in Table S5.7. 


\subsection{Modeling of Energy Use Impacts of Lightweighted US Vehicle Fleet}

The net energy savings during the life of a lightweighted vehicle also requires a calculation of use-phase energy savings that occur due to reduced fuel usage during the vehicle operation. Prior studies have examined the relationship between vehicle mass reduction and fuel economy improvements for different types of vehicles. ${ }^{16,45-47}$ The fuel savings estimates adopted for this study are based on the WorldAutoSteel Energy and GHG model for mid-size vehicles, using a US driving cycle (SAE J1711) and accounting for engine resizing to maintain constant 0-100 $\mathrm{km} / \mathrm{h}$ acceleration. ${ }^{48}$ Use-phase savings are calculated by applying these relationships to the mass reductions considered in Tables 1 and 2 for different lightweight vehicles. Further discussion and assumptions are shown in the SI, Section S6.

The use-phase savings are combined with the average of the low- and high-energy pathway manufacturing energy intensity data (Table S6.2 in SI) to calculate net energy savings both at the level of a vehicle and cumulative U.S. light-duty vehicle fleet as shown in the SI Table S6.2 and S6.3, respectively. We calculate net energy savings over the life of a standard vehicle and project net energy impacts from 2010-2050 for the US light-duty vehicle fleet. Argonne National Laboratory's VISION model is used to estimate the fleet-wide use-phase energy consumption for each lightweight vehicle type. The VISION model was developed by the Argonne and the US Department of Energy to project potential energy use impacts of new vehicle technologies and fuels through $2050 .{ }^{44}$ It tracks the composition of the vehicle fleet over time, accounting for vehicle ages and fleet turnover, fuel economy projections for different vehicle classes and drivetrains, and vehicle miles traveled (VMT), which varies by vehicle age, over time and in response to fuel costs. It then uses the results from a run of Argonne's GREET model to calculate primary energy associated with different fuel savings. ${ }^{43}$ The projected fuel mix for 
electricity generation was based on AEO 2012. ${ }^{49}$ Further details about the assumptions included in VISION are in the SI, Sect. S7.

We examine nine conventional vehicle lightweighting and four alternative vehicle lightweighting scenarios covering the different types of lightweight vehicles shown in Table 1 and Table 2 . In each scenario, new vehicle sales gradually transition from baseline to lightweight vehicles following a Bass curve, with adoption rates that are consistent with past adoption of other vehicle technologies. ${ }^{50-51}$ Incorporation of these lightweight vehicles into the fleet then follows the fleet turnover model from VISION. In exploring the effects of lightweighting alternative fuel vehicles, we also examine two scenarios for adoptions of alternative fuel vehicles from 2012-2050: a market scenario based on the Annual Energy Outlook labeled "AEO" (considered as the baseline) and another based on DOE's Transportation Energy Futures (TEF) study ${ }^{52}$ labeled "TEF". The TEF scenario assumes a more aggressive adoption of alternative-powertrain vehicles. Further details about the assumed adoption rate of lightweight vehicles and the alternative fuel vehicle scenarios are in the SI, Sect. S8.

\section{RESULTS}

\subsection{Energy Impacts per Lightweighted Vehicle}

The net energy savings potential from lightweighting a $1776 \mathrm{~kg}$ conventional powertrain vehicle with an operation lifetime of 200,000 km is shown in Figures 2(A) and 2(B) and the detailed results are shown in the SI, Table 6.2. A baseline vehicle CED is considered as a benchmark to calculate net energy saving potentials of lightweighted vehicle types. For all conventional and alternative powertrain lightweighted vehicle scenarios considered in this study, the net energy savings potential is calculated as the sum of net energy savings potential of vehicle manufacturing and operation as per equation (1) shown here. 


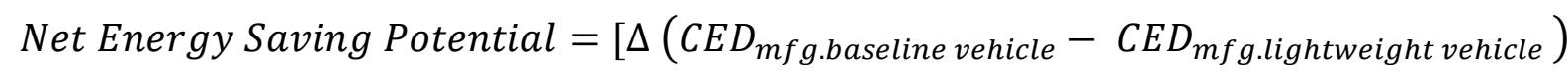

$\left.+\Delta\left(C E D_{\text {opn.baseline vehicle }}-C E D_{\text {opn.lightweight vehicle }}\right)\right]$

The first-line, right hand part of the above equation represents the CED difference in manufacturing a baseline vehicle and a respective lightweighted vehicle, which is positive in cases only when manufacturing CED of a lightweighted vehicle is lower than baseline. On the other hand, the mass-induced fuel consumption reduction results in vehicle operation stage energy savings in all lightweighted vehicles. Net energy savings potential value is always positive as the energy incurred to operate a baseline vehicle is always higher than any lightweighted vehicle, and the vehicle operation energy savings is significantly greater even in lightweight vehicles with an energy penalty at the vehicle manufacturing stage. In other words, net energy savings potential is an indicator used to justify the selection of one material versus another to lightweight a vehicle.

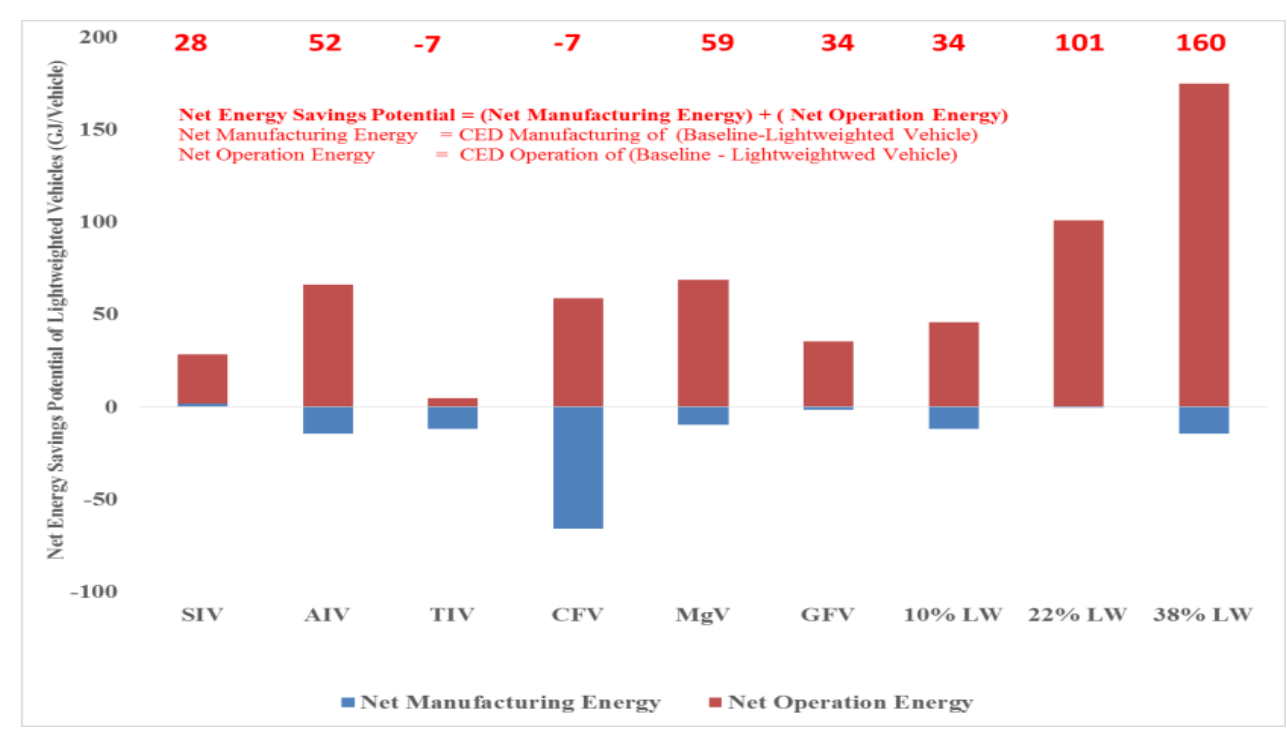

Figure 2(A) Net energy savings potential for conventional lightweighted vehicles 


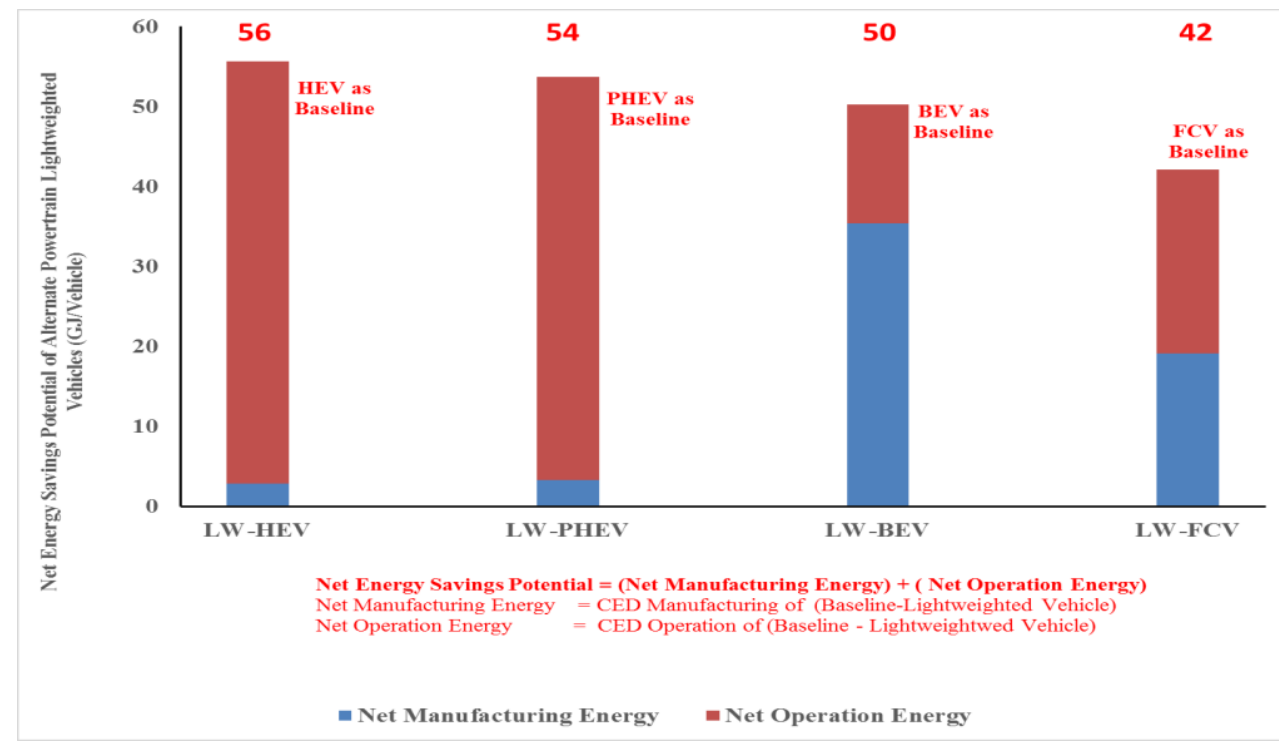

Figure 2 (B) Net energy savings potentials for alternative lightweighted vehicles

Among conventional lightweighted vehicle scenarios (Figure 2A), the net energy savings potential of 38\% LW vehicle is highest ( 160 GJ/vehicle) followed by $22 \% \mathrm{LW}$ vehicle (101 GJ/vehicle). This is mainly attributed to large energy savings achieved in use stage due to significantly lower vehicle weight compared to baseline. Following these in terms of net energy savings are $\mathrm{AIV}$ and $\mathrm{MgV}$ vehicle scenarios. The net energy savings potential is similar for these two vehicle scenarios and is around 50-60 GJ/vehicle. A similar trend is observed in terms of energy saved for these two scenarios because: (a) their weight reduction potentials compared to baseline vehicle is similar and (b) their manufacturing energy footprint via low and high energy pathways is also comparable, based on the assumptions made to quantify them (more details provided in the SI, Sect. S5). Net energy savings per vehicle are for SIV, GFV, and 10\% LW scenarios are observed to be moderate. But for CFV and TIV scenarios, the lightweighting does not yield any benefits due to significantly high energy footprints associated with manufacturing of carbon fiber polymer composite and titanium alloy based auto parts. Although both vehicle scenarios have negative energy savings, one major difference between the two is the assumed 
weight reduction potential compared to baseline. Since The TIV weight is only $1 \%$ lower than baseline vehicle, there is no net energy savings in this case. On the other hand, for the CFV vehicle with its of $13 \%$ mass savings over the baseline vehicle, the level of energy savings during vehicle operation is less than the vehicle manufacturing energy use. With an introduction of newer high speed and lower energy intensive technologies (e.g. continuous carbon fiber reinforced melt impregnated thermoplastic unidirectional material forms), the energy of footprints of making carbon fiber composite parts is expected to be lowered in near future. The net energy savings potentials of lightweighted alternative powertrain vehicles with respect to the corresponding baseline are shown in Figure 2(B), e.g. HEV for LW-HEV. The net energy savings of both LW-HEV and LW-PHEV are almost similar with majority of savings are realized during the vehicle use stage. On the other hand, in case of LW-BEV the net energy savings obtained is slightly lower, i.e., $50 \mathrm{GJ} / \mathrm{vehicle,} \mathrm{of} \mathrm{which} 70 \%$ of savings are attributed to the vehicle manufacturing stage. This reduction in manufacturing energy footprint in LW-BEV is attributed to lower weight requirements of Li-ion battery (a $147 \mathrm{~kg}$ mass decrease in battery components) when compared to BEV which is apparently most energy intensive in this vehicle configuration. Unlike other lightweighted alternative powertrain vehicles, the use stage energy savings of LW-BEV are not significant compared to baseline BEV because of the smaller fuel reduction value associated with these vehicles. Finally, net energy savings potential of a LWFCV is $42 \mathrm{GJ}$, of which $45 \%$ of energy savings is contributed from manufacturing stage and the rest from the use stage.

\subsection{U.S. Fleet-level Vehicle Manufacturing and Use Energy Impacts}

The energy savings potential of the US fleet of light-duty vehicles from 2012-2050 is estimated using the VISION model in which the influence of other parameters such as the vehicle adoption 
rate is taken into consideration. Estimated cumulative energy consumptions from 2010 to 2050 for all the scenarios, including the baseline scenario without lightweighting, are provided in the SI, Table S6.3. Values are reported for both the low- and high-energy pathways of vehicle manufacturing energy. The vehicle manufacturing energy consumption averages 14\% (lowenergy pathway) and 18\% (high-energy pathway) of the cumulative energy consumption, with a low of 11.8\% (lightweighting BEVs in AEO scenario) and a high of 22.3\% (lightweighting PHEVs in TEF scenario). Figure 3A shows the estimated energy-savings potential, relative to the baseline, for each of the nine conventional powertrain LW vehicles, using the AEO market scenario and the average vehicle manufacturing pathway.

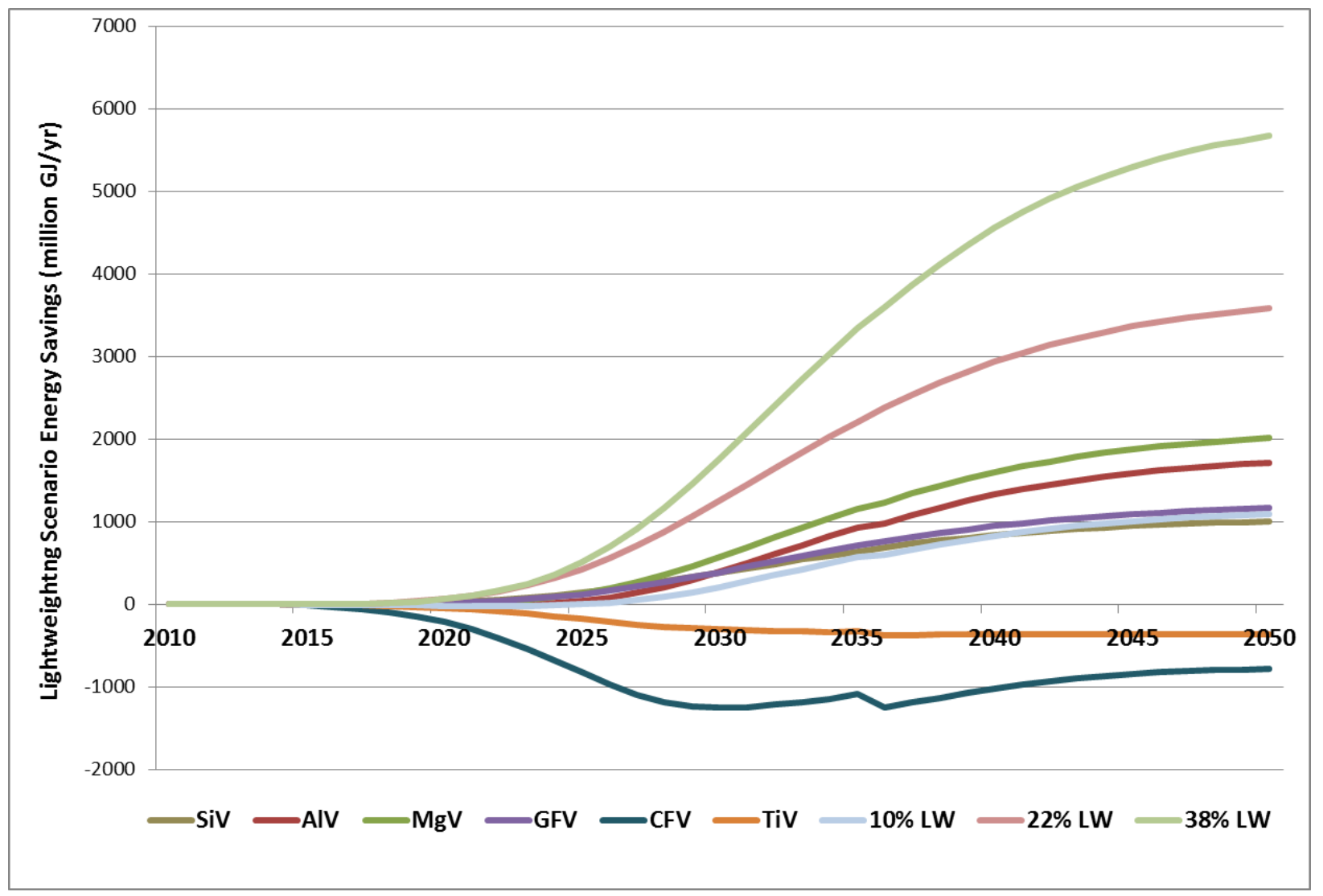

Figure 3A Annual fleet-level energy savings for conventional powertrain vehicle lightweighting scenarios. 


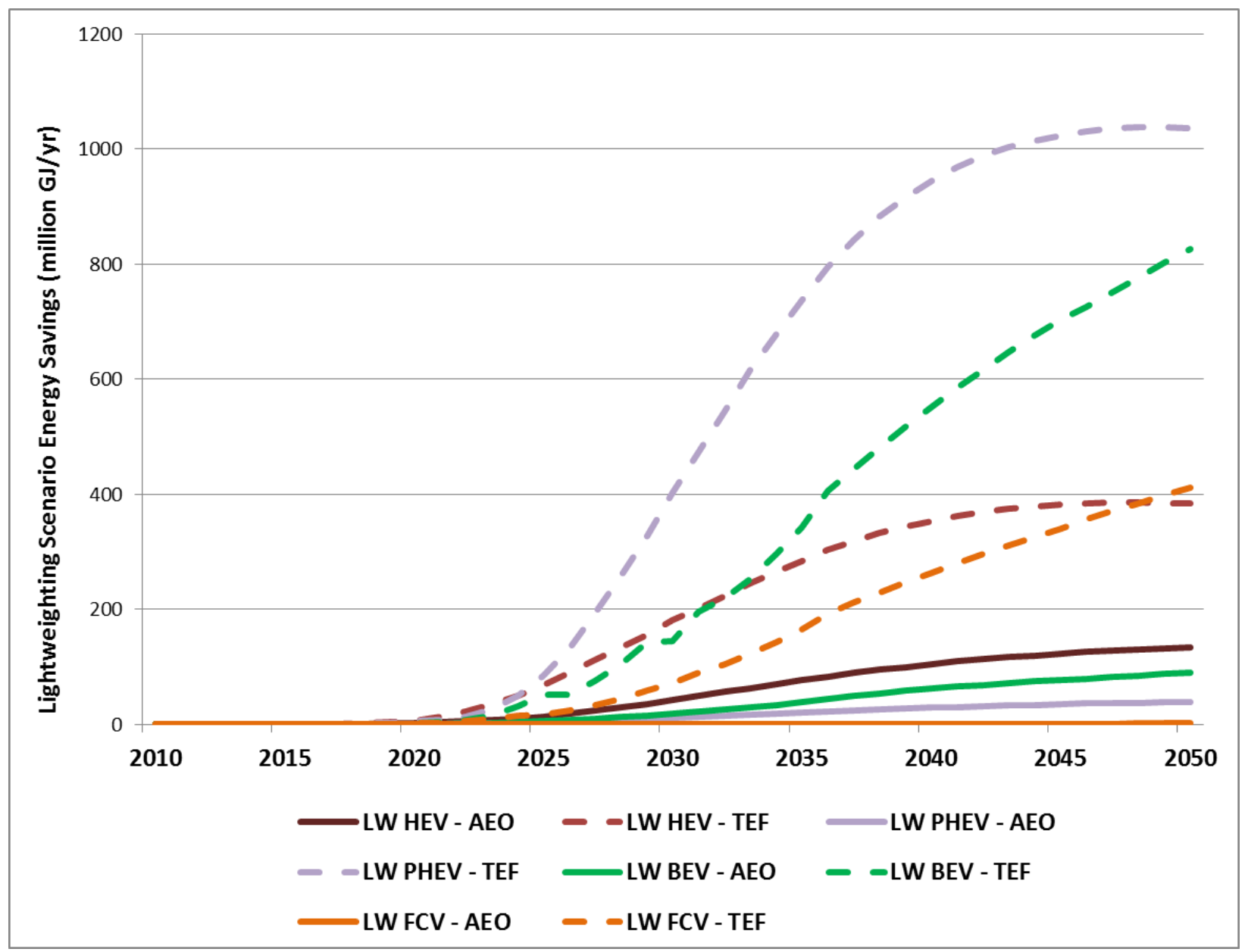

Figure 3B Annual fleet-level energy savings of alternative powertrain vehicle lightweighting scenarios.

For conventional vehicles, the multi-material 38\% LW vehicle achieves the highest cumulative energy savings (94 billion GJ) over the period 2010-2050. For this vehicle, the annual energy savings by 2050 are estimated to be 5.7 billion GJ/year, representing a $19 \%$ reduction in fleet energy consumption compared to the baseline without lightweighting. The single materials that show the highest energy savings potential are magnesium and aluminum. The TIV and CFV show no positive energy savings over the same period due to the high energy intensity of manufacturing these materials. Titanium has the highest embodied energy content of the materials studied, and the TIV has the lowest level of lightweighting resulting in TIV having the 
lowest use-phase energy savings among the conventional powertrain lightweight vehicles studied. The use-phase energy consumption of the CFV is low, though not low enough to offset the manufacturing energy use which is the highest among all lightweight vehicles. In all other vehicles, especially the $38 \% \mathrm{LW}$ and $22 \% \mathrm{LW}$, the vehicle use phase savings outweigh any increases in vehicle manufacturing energy consumption. Even in the worst case (i.e., CFV), the energy penalty decreases over time as more of the vehicle fleet is replaced by lightweight vehicles. The kink in 2036 is due to VISION's approach to extending the AEO vehicle production forecasts beyond 2035, which leads to a jump in vehicle production (and therefore manufacturing energy use) in 2036.

The energy impacts of LW alternative powertrain vehicles are explored in both the AEO and TEF market scenarios for each LW alternative powertrain vehicle, using the average of the lowand high-pathway energy consumption data, with the use-phase values calculated using the VISION model. Figure 3B shows the estimated energy savings potential per vehicle scenario by year, relative to the associated vehicle references without LW (e.g., LW HEV compared to HEV; LW PHEV compared to PHEV, etc.), for each of the four LW alternative powertrain vehicles, the average vehicle manufacturing pathway, and two market scenarios. The energy reductions are significantly higher for the TEF market scenarios because TEF projects higher adoption rates for alternative powertrain vehicles than does the AEO scenario. The LW HEV has the highest savings potential among vehicles in the AEO market scenario because of its higher market share in the AEO projections. Among all alternative powertrain vehicle scenarios evaluated, the LW PHEV-TEF scenario, because of its larger market share, has the highest savings potential, estimated to achieve cumulative energy savings of 19 billion GJ during the period 2010 to 2050. By 2050, the annual energy savings achieved from lightweighting is 1.0 billion GJ/yr for the LW 
PHEV-TEF scenario and represents a $4.5 \%$ reduction in energy consumption compared to the TEF market scenario without lightweighting.

A final scenario of lightweighting of all light-duty conventional and alternative-powertrain vehicles for the AEO and TEF market scenarios (All-AEO and All-TEF) was considered. For this combined scenario, the $22 \% \mathrm{LW}$ vehicle was assumed for conventional-powertrain vehicles, and the LW HEV, LW PHEV, LW BEV, and LW FCV were assumed for alternative powertrain vehicles. Results show that the annual energy savings effects of vehicle lightweighting are greater for the conventional-vehicle dominated AEO market scenario (“All-AEO Lightweighting" curve in Figure 4) than for the alternative-vehicle-dominated TEF market scenario (“All-TEF - Lightweighting"). The estimated cumulative total energy savings from 2010 to 2050 for the All-AEO-Lightweighting scenario are 66.1 billion GJ and for the All-TEFLightweighting scenario are 54.8 billion GJ. The objective of this study was to evaluate the impacts of vehicle lightweighting and not to compare the AEO and TEF market cases. However, not considering the energy savings associated with alternative powertrains compared to their conventional counterparts could be misleading. To address this gap, a third curve is added to Figure 4 (denoted as "All-TEF - Powertrain Savings") to represent the estimated energy savings of alternative powertrains without vehicle lightweighting in the TEF market scenario. The cumulative energy savings over the period 2010-2050 for the All-TEF scenario from both lightweighting and powertrain savings is estimated to be 189 billion GJ. 


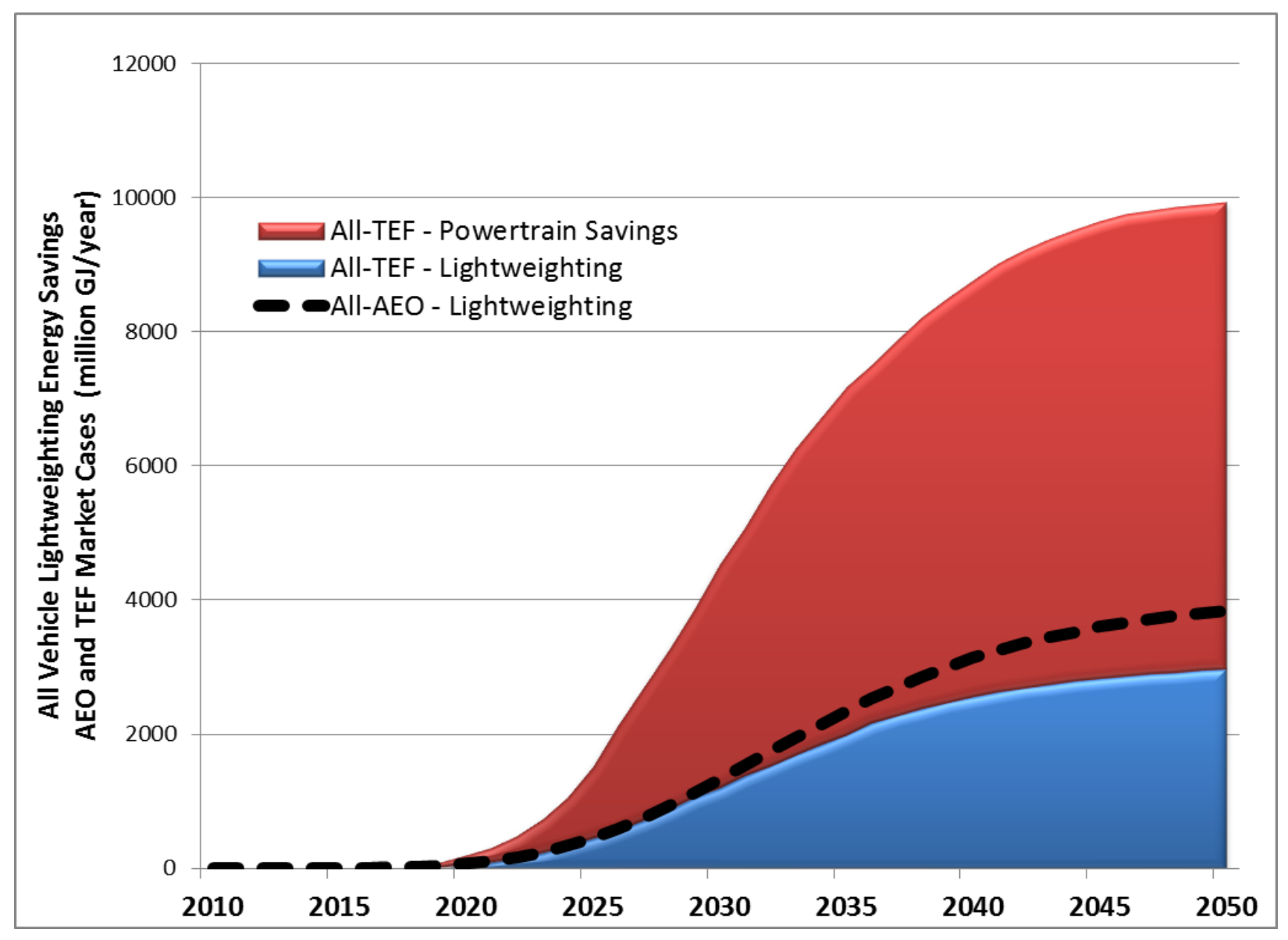

Figure 4. All-vehicle lightweighting scenario - annual energy savings

\section{Discussion}

With the growing trend in vehicle lightweighting for meeting new fuel economy standards, total per-vehicle manufacturing energy increases when materials of high energy intensity are used in place of conventional mild steel. Manufacturing energy for each of the lightweight conventional powertrain vehicles, except for SIV and GFV, increases with a range of $11-160 \mathrm{GJ} / \mathrm{vehicle}$. The opportunities to apply each specific material type affect the amount of the material used in the LW vehicle scenario, which in turn affects weight reduction and manufacturing energy changes. The materials' recyclability, manufacturing inputs and processes considered under the low- and high-energy pathways have significant manufacturing energy impacts, e.g., all three of the multi 
material LW vehicles provide manufacturing energy savings under the low-energy pathway but exceed baseline vehicle CED under the high-energy pathway. Low- and high-energy pathway differences are most pronounced in vehicles using significant amounts of energy-intensive magnesium or carbon fiber with no recycled content. This includes the $\mathrm{CFV}, \mathrm{MgV}$, and $38 \% \mathrm{LW}$ vehicle. A significant manufacturing energy reduction opportunity of $84 \mathrm{GJ} /$ vehicle exists for the CFV if lignin, an alternative, renewable precursor, is used. It is also likely that even a small fraction of carbon fiber recycled content in the CFV would improve the manufacturing energy use. A recent life cycle assessment of carbon fiber-reinforced polymer composites indicates an overall $30 \%$ reduction in life cycle energy use using a pyrolytic recycling method for the end-oflife carbon fiber composites recycling. ${ }^{42}$ Likewise, the use of recycled aluminum in the lowenergy pathway significantly reduces energy demand for scenarios that rely on cast aluminum, such as the AIV and the $22 \% \mathrm{LW}$ vehicle for which the manufacturing CED varies by 40 GJ/vehicle depending on the energy pathway.

The results of the vehicle lightweighting scenarios assessments are consistent with earlier findings that the major benefits of vehicle lightweighting lie in the vehicle operation phase. ${ }^{53}$ For most of the nine lightweighting conventional powertrains, use phase energy benefits under the AEO market case are significantly higher than the manufacturing phase increases and result in an overall life cycle energy savings.

Because alternative powertrain vehicles already have less wasted energy due to their efficient powertrains and regenerative braking, lightweighting these vehicles provides less use phase energy savings than the savings provided by lightweighting conventional powertrain vehicles. For most alternative powertrain vehicles, including the lightweighted vehicles, manufacturing CED are greater than those of the baseline vehicle because of the energy intensity of their 
powertrain components. Lightweighting reduces the manufacturing CED of most of the alternative powertrain vehicles under both energy pathways with an exception of a significantly less benefits for the HEV and PHEV benefits from lightweighting. The significantly higher penetration of alternative powertrain vehicles such as in the TEF market case produces greater energy benefits from lightweighting alternative vehicles than those associated with the AEO market case. With both lightweighting and higher efficiency drivetrains considered in the TEF market case, annual energy savings of 11.2 billion GJ/yr could be realized by 2050 , a $39 \%$ reduction relative to the AEO market case with no lightweighting. Fuel reduction benefits of lightweighting are about $33 \%$ of the energy savings associated with lightweighted alternative powertrains, or, in other words, $25 \%$ of the total savings can be attributed to lightweighting.

\section{ASSOCIATED CONTENT}

\section{Supporting Information}

$\mathrm{S} 1-\mathrm{S} 8$.

\section{ACKNOWLEDGEMENTS}

THIS FESEARCH WAS SPONSORED BY THE U.S. DEPARIMENTOFENERGY, OHAE OF ENERGY EHAENCY AND RENEWABIE ENERGY, ADVANCED MANUFACIURNG OHTCE. 


\section{REFERENCES}

1. Singh, H. Mass Reduction for Light-Duty Vehicles for Model Years 2017-2025, Report No. DOT HS 811 666, Electricore, Inc., 2012.

2. McKinsey \& Company. Lightweight, heavy impact; McKinsey Advanced Industries Sector: 2012; www.autoassembly.mckinsey.com/html/resources/publications.asp.

3. National Research Council (NRC). Assessment of fuel economy technologies for light-duty vehicles; The National Academies Press: Washington, DC, 2011.

4. Lotus Engg. Inc. (Lotus). An assessment of mass reduction opportunities for a 2017-2020 model year vehicle program; International Council on Clean Transportation: Mar. 2010.

5. Lutsey, N. Review of technical literature and trends related to automobile mass-reduction technology, Report No. UCD-ITS-RR-10-10, Institute of Transportation Studies: University of California, Davis, CA, May. 2010.

6. Environmental Protection Agency and National Highway Traffic Safety Administration (EPA/NHTSA). Joint technical support document: rulemaking to establish light-duty vehicle greenhouse gas emission standards and corporate average fuel economy; Environmental Protection Agency and National Highway Traffic Safety Administration: Washington, DC, 2010. 7. White, M. Showcasing successful high volume application of aluminum into body-in-white: demonstrating weight saving opportunities using aluminum; paper presented at the Global Automotive Lightweight Materials conference: London, UK. Apr 24-25 2013.

8. Franzen, M. Developing multi-material vehicles with composite parts to identify significant weight reduction opportunities; paper presented at the Global Automotive Lightweight Materials conference: London, UK. Apr 24-25 2013. 
9. Frost \& Sullivan. Global analysis of weight reduction strategies of major OEMs; Market Engineering Research: 2009.

10. Birch, S. BMW i3, the inside story: What it's made of, how it's made, Automotive Engineering Intl. 2013 34-36, June 4.

11. Keoleian, G,; Shelie Miller, R. D.; Kleine, A. F., and Janet M.. "Life cycle material data update for GREET model." Report No. CSS12-12. 2012.

12. Moon, Paula, Andrew Burnham, and Michael Wang. Vehicle-cycle energy and emission effects of conventional and advanced vehicles. No. 2006-01-0375. SAE Technical Paper, 2006.

13. Schmidt, Wulf-Peter, Elisabeth D.; Matthias F.; Stephan K.; Silvia L.; Dirk O.; Sophie P.; and Christian, T. "Life cycle assessment of lightweight and end-of-life scenarios for generic compact class passenger vehicles." The International Journal of Life Cycle Assessment 9, no. 6 (2004): 405-416.

14. Duflou, J. R.; Jozef De M., Ignace, V.; and Wim D. "Environmental impact analysis of composite use in car manufacturing." CIRP Annals-Manufacturing Technology 58, no. 1 (2009): $9-12$.

15. Witik, R. A.; Jérôme, P.; Véronique M.; Christian L.; and Jan-Anders E. M. "Assessing the life cycle costs and environmental performance of lightweight materials in automobile applications." Composites Part A: Applied Science and Manufacturing 42, no. 11 (2011): 16941709.

16. Cheah, Lynette, John Heywood, and Randolph Kirchain. "The energy impact of US passenger vehicle fuel economy standards." In Sustainable Systems and Technology (ISSST), 2010 IEEE International Symposium on, pp. 1-6. IEEE, 2010. 
17. Lloyd, Shannon M., and Lester B. Lave. "Life cycle economic and environmental implications of using nanocomposites in automobiles." Environmental Science \& Technology 37, no. 15 (2003): 3458-3466.

18. Koffler, Christoph, and Klaus Rohde-Brandenburger. "On the calculation of fuel savings through lightweight design in automotive life cycle assessments." The International Journal of Life Cycle Assessment 15, no. 1 (2010): 128-135.

19. Stodolsky, F.; Gaines, L; Cuenca, R.; Vyas, A.. Life-cycle energy savings potential from aluminum-intensive vehicles. Vol. 951837. Warrendale, PA: SAE, 1995.

20. Das, Sujit. "The life-cycle impacts of aluminum body-in-white automotive material." JOM 52, no. 8 (2000): 41-44.

21. Zini, G. "Why Should Aluminum Continue to Replace in Steel Cars? A LCA Comparison." Proceedings of $22^{\text {nd }}$ International Technical Conference on Enhanced Safety Vehicles, Paper Number 11-0167. 2013.

22. Coleman, N; and Geyer, R. "Sustainability, Global Warming and Life Cycle Perspective on Material Selection in Vehicle Design." $7^{\text {th }}$ International Conference on Materials for Lean Weight Vehicles, LWV7, Warwick, Dec 11-12, 2007.

23. Hakamada M,; Furuta, T.; Chino, Y.; Chen, Y.; Kusuda, H.; Mabuchi, M. . Life Cycle Inventory Study of Magnesium Alloy Substitution in Vehicles, Energy 2007, 32, 1352-1360.

24. Shaw, J. NHTSA's Light Weight Vehicle (LWV) Multi-Material Lightweighting Analysis, United States Steel Corporation, www.autosteel.org, 2013.

25. Hawkins, T. R.; Singh, B.; Majeau-Bettez, G.; Stromman, AH. "Comparative Environmental Life Cycle Assessment of Conventional and Electric Vehicles," Journal of Industrial Ecology 2012, 17(1), 53-64. 
26. PE International. "Life Cycle CO2 e Assessment of Low Carbon Cars, 2020-2030.” Final Report for the Low Carbon Vehicle Partnership. Stuttgart, Germany, 2013.

27. Energetics Inc. Energy use benchmarking in the automotive supply chain case study; report U.S. Dept. of Energy, Industrial Technology Programs: Dec. 2009.

28. Sathaye, J. A.; Lecocq, F.; Masanet, E.; Najam, A.; Schaeffer, R.; Swart, R.; Winkler, H. Opportunities to change development pathways towards lower greenhouse gas emissions through energy efficiency. Journal of Energy Efficiency 2009, 2(4), 317-337.

29. Ward's Communications (Ward). United States vehicle production by manufacturer, Ward's Communications: 2013; www.wardsauto.com.

30. Sullivan, J. L.; Burnham, A.; Wang, M. Energy-consumption and carbon-emission analysis of vehicle and component manufacturing; Center for Transportation Research, Energy Systems Division: Argonne National Laboratory, IL, Sept. 2010.

31. U.S. Census Bureau. Annual survey of manufactures: general statistics: statistics for industry groups and industries: 2011 and 2010; U.S. Census Bureau: 2011.

32. Energy Information Administration (EIA). Annual energy review 2011, Energy Information Administration: 2011; www.eia.gov/totalenergy/data/annual/pdf/sec2_3.pdf.

33. U.S. Dept. of Energy (DOE). Technology roadmap for energy reduction in automotive manufacturing; U.S. Dept. of Energy: Sept. 2008.

34. Ducker Worldwide. Aluminum in 2012 North American light vehicles: Executive summary, presentation to Aluminum in Transportation; The Aluminum Association, Inc.: Sept. 72011.

35.WorldAutoSteel. Futuresteelvehicle: Overview report; WorldAutoSteel: Apr. 2011; www.c315221.r21.cf1.rackcdn.com/FSV_OverviewReport_Phase2_FINAL_20110430.pdf, on $3 / 21 / 13$. 
36. EDAG . VENZA aluminum BIW concept study; Presentation to the Aluminum Association, Jan. 232013.

37. United States Automotive Materials Partnership (USAMP). Magnesium vision 2020: a North American automotive strategic vision for magnesium; United States Automotive Materials Partnership: Nov. 1, 2006.

38. Friedrich H.; Kiese, J.; Haldenwanger, H.-G.; Stich, A. Titanium in Automotive Applications-Nightmare, Vision or Reality, ed. G. Lutjering; Weinheim, Germany, Wiley-VCH, 2003.

39. Energy and Environmental Analysis, Inc. (EEA). Analysis of light duty vehicle weight reduction potential, draft final report; US Department of Energy, Office of Policy: Arlington, VA; July 2007.

40. Das, S. Cost effectiveness of a $25 \%$ vehicle mass reduction goal in light-duty vehicles, draft report; U.S. Department of Energy, Lightweight Materials \& Propulsion Materials, Vehicle Technologies Program: Washington, DC, Sept 2012.

41.Azom Titanium alloys-Ti6Al4V grade 5. July 10 2013;

www.azom.com/properties.aspx?ArticleID $=1547$

42. Das, S. Life cycle assessment of carbon fiber reinforced polymer composites. Int. J. Life Cycle Assess 2011, 16, 268-282.

43. Argonne National Laboratory (ANL). The Greenhouse Gases, Regulated Emissions, and Energy Use in Transportation; (GREET2_2012); Argonne National Laboratory: Argonne, IL, 2012.

44. Ward, J., Vyas, A., and Singh, M. Vision 2008 user's guide, Argonne National Laboratory report ANL-08/34: 2008. 
45. Brooker, A.D.; Ward, J., Wang, L. Lightweighting impacts on fuel economy, cost, and component losses. SAE International 2013, 2013-01-0281.

46. Koffler, C.; Rhode-Brandenburger, K. On the calculation of fuel savings through lightweight design in automotive life cycle assessments. Int J Life Cycle Assess 2010, 15, 128-135.

47. Pagerit, S.; Sharer, P.; Rousseau, A. Fuel economy sensitivity to vehicle mass for advanced vehicle powertrains; Society of Automotive Engineers: 2006, 2006-01-0665.

48. Geyer, R. User guide for version 3 of the WorldAutoSteel energy and GHG model; University of California at Santa Barbara, CA, Jan. 6, 2012.

49. U.S. Energy Information Administration (EIA). Annual energy outlook 2012 with projections to 2035. June 2012, DOE/EIA-0383(2012).

50. Environmental Protection Agency (EPA). Light-duty automotive technology, carbon dioxide emissions, and fuel economy trends: 1975 through 2009; Environmental Protection Agency: 2009; EPA 420-R-09-014.

51. Plotkin, S.; Stephens, T.; McManus, W. Vehicle technology deployment pathways: an examination of timing and investment constraints, transportation energy futures report series;

52. Department of Energy (DOE). Transportation energy futures project; Department Of Energy: 2013; www1.eere.energy.gov/analysis/transportationenergyfutures/

53. Kim, H.C; Wallington, T.J. Life-cycle energy and greenhouse gas emission benefits of lightweighting in automobiles: Review and harmonization. Environmental Science and Technology 2013, 47(12) 6089-6097. 